Int. J. Morphol.,

31(3):813-818, 2013.

\title{
Arabian Oryx (Oryx leucoryx) Trachea: a Descriptive and Morphometric Analysis
}

\author{
Tráquea del Órix de Arabia (Oryx leucoryx): un Análisis Descriptivo y Morfométrico
}

Mohammad Borhan Al-Zhgoul"; Abdul Hafeed S. Dalab*; ElJarah Abdulhakeem**; Zuhair Bani Ismail"** Al Thanain Thanain ${ }^{* * * *}$

AL-ZHGOUL, M. B.; DALAB, A. H. S.; ABDULHAKEEM, E.; ISMAIL, Z. B. \& THANAIN, A. Arabian oryx (Oryx leucoryx) trachea: a descriptive and morphometric analysis. Int. J. Morphol., 31(3):813-818, 2013.

SUMMARY: The objective of this study was to report the distinctive anatomical and histological features of the trachea of the Arabian Oryx (Oryx leucoryx). The number of tracheal rings and tracheal length were measured. The diameter, thickness and cross sectional area of tracheal ring were determined at four tracheal regions (cranial cervical (CCR), middle cervical, thoracic inlets and intra thoracic). Tracheal rings were also collected for histological analysis. The mean length of the trachea was $54.1 \mathrm{~cm} \pm 0.73$, while the number of tracheal rings varied from 50-51. Tracheal ring measurements (diameter, thickness and cross sectional area) were smallest at the thoracic inlet region. The ratio of the outer transverse to outer vertical and inner transverse to inner vertical diameter ranged between 0.75 and 0.98 . The histological analysis revealed that the wall of the trachea consists from four histological layers: a mucosa made of pseudostratified epithelium and lamina propria, submucosa made of dense irregular connective tissue, a hyaline cartilage and a tunica adventitia made of loose connective tissue.

KEY WORDS: Oryx leucoryx; Trachea; Descriptive analysis; Morphometric analysis.

\section{INTRODUCTION}

The Arabian oryx (Oryx leucoryx) is endangered wild antelope that belongs to the family Bovidae and subfamily Hippotraginae. In the Middle East, the oryx has historically lived in Jordan, Syria, Iraq, Israel, Sinai and the Arabian peninsula (Eljarah et al., 2012b). Because of its current classification as an endangered species (Eljarah et al., 2012a), most of the remaining population is under strict observation in reservoirs. Wildlife veterinarians working on such species are faced with grimly limited clinical, physiological and anatomical information in literature. The trachea makes a significant portion of the conducting airways. In addition to its vital role in breathing, variations in the anatomy of the trachea between different animal species and between individuals could have significant importance in veterinary clinics (Chunder et al., 2010). Knowledge of the diameter and length of the trachea is essential in the proper selection of endotracheal tube size used for delivery of anesthetic gases during general anesthesia (Al-Zghoul et al., 2006). In addition, this knowledge aids clinicians in choosing the proper size of tracheostomy tubes used in emergency situations. Inappropriate selection of tube size has been associated with pressure necrosis, irritation, esophagealtracheal fistula and tracheal stenosis Knudson, 1975; Brodsky et al., 1996; Behl \& Watt, 2005).The diameter and length of the trachea has been reported for several domestic and wildlife animal species (Peshin \& Prakash, 1975; Dallman \& Brown, 1984; Art \& Lekeux, 1991; Kumar et al., 1992; Dapanoglu \& Kara, 2001; Kalache et al., 2001; Loewen \& Walner, 2001; Al-Zghoul et al.; Ivana \& William, 2009). To our knowledge, there are no published data regarding the normal anatomy of the trachea of the Arabian oryx, therefore the main objective of this study was to report a comprehensive descriptive and morphometric analysis of the trachea of the Arabian oryx.

\section{MATERIAL AND METHOD}

The trachea of 3 adult (7-9 years of age) male Arabian oryx were obtained from animal cadavers presented to the Veterinary Health Center of the Faculty of Veterinary Medi-

\footnotetext{
* Department of Basic Medical Veterinary Sciences, Jordan University of Science and Technology, Irbid, Jordan.

** Department of Veterinary Clinical Sciences, Jordan University of Science and Technology, Irbid, Jordan.

**** Department of Anatomy, King Faisal University, Kingdom of Saudi Arabia.
} 
cine at Jordan University of Science and Technology for necropsy. The length of the trachea was measured from the cranial border of the first tracheal ring to the tracheal bifurcation and the total number of the tracheal rings was reported. The trachea was then incised open through the annular ligament and the following measurements were made using a digital caliper: the outer transverse (OT), inner transverse (IT), outer vertical (OV) and inner vertical (IV) diameters (Fig 1).

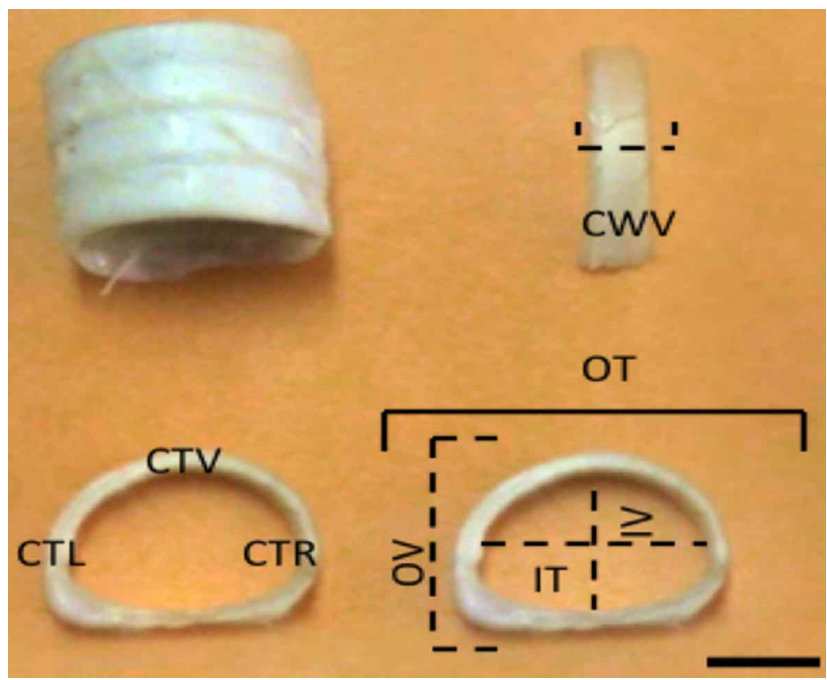

Fig. 1. Images represent where the inner transverse (JT), outer transverse (OT), inner vertical (IV) and outer vertical (OV) diameters and the cartilage thickness of the left (CTL), right (CTR) and ventral CTV) midpoints of the tracheal ring were measured.

Cartilage thickness was measured at the left (CTL), right (CTR) and ventral (CTV) midpoints of each tracheal ring. The ventral width of the tracheal rings (CWV) was also measured. In addition, using digital image analysis (Adobe Systems, San Jose, CA), the cross-sectioned area (CSA) was measured as described before (Al-Zghoul et al.). For the histological analysis, full thickness specimens were obtained from different regions. The tissues were fixed in $10 \%$ phosphate-buffered formaldehyde and paraffin embedded. Sections $4 \mu \mathrm{m}$ thicken were stained with hematoxylin and eosin stain for histopathological evaluation using light microscopy.

Statistical analysis. Data are presented as mean \pm standard deviation (SD). Data from the four tracheal regions (cranial cervical (CCR), middle cervical (MCR), thoracic inlet (TIR) and intrathoracic (ITR)) were analyzed using non-parametric one-way analysis of variance followed by Bonferroni multiple range test (IBM SPSS software, Chicago, USA). Differences were considered significant at $\mathrm{P}<0.05$.

\section{RESULTS}

The mean $( \pm \mathrm{SD})$ tracheal length from the first to the last tracheal ring was $54.1 \pm 0.73 \mathrm{~cm}$ and the number of the tracheal rings varied from 50 to 51 . Tracheal ring fusion with neighboring rings was observed within the cranial cervical region and to a lesser degree in other regions.

The mean values of the diameters for the four regions of the trachea are summarized in Table I. The outer and inner vertical diameters decreased caudally until the thoracic inlet region and increased again in the intrathoracic region. The highest values of the outer and inner vertical diameters were in the intrarthoracic region and the lowest values in the thoracic inlet region. The highest values of the outer and inner transverse diameters were in the cranial cervical region and the lowest values in the thoracic inlet region. The ratios of transverse to vertical inner and outer diameters lay between 0.75 and 0.98 in all regions.

The mean values of cartilage thickness for the right, left and ventral midpoints and the ventral width of the tracheal rings are presented in Table II. The cartilage thickness at the right and left midpoints was least at the

Table I. Mean \pm SD $(n=6)$ of outer vertical (OV), outer transverse (OT), inner vertical (IV), inner transverse (IT) diameters, and ratios of OT /OV and IT /IV in the 4 regions of the trachea; cranial cervical (CCR), middle cervical (MCR), thoracic inlet (TIR) and the intrathoracic (ITR).

\begin{tabular}{lllll}
\hline Parameter & CCR & MCR & TIR & ITR \\
\hline OV $(\mathrm{mm})$ & $26.78 \pm 1.39$ & $23.78 \pm 0.42$ & $23.16 \pm 1.61$ & $28.43 \pm 2.07$ \\
OT $(\mathrm{mm})$ & $24.05 \pm 1.70$ & $21.88 \pm 2.78$ & $21.47 \pm 1.84$ & $23.35 \pm 1.71$ \\
OT/OV & $0.90 \pm 0.12$ & $0.92 \pm 0.15$ & $0.93 \pm 0.18$ & $0.82 \pm 0.21$ \\
IV $(\mathrm{mm})$ & $22.17 \pm 1.28$ & $20.31 \pm 1.11$ & $20.13 \pm 1.10$ & $22.42 \pm 1.54$ \\
IT $(\mathrm{mm})$ & $20.96 \pm 1.18$ & $19.96 \pm 1.19$ & $15.07 \pm 1.14$ & $19.51 \pm 2.13$ \\
IT/IV & $0.95 \pm 0.14$ & $0.98 \pm 0.13$ & $0.75 \pm .0 .10$ & $0.88 \pm 0.13$
\end{tabular}


thoracic inlet. The cartilage thickness at the ventral midpoint decreases caudally until the thoracic inlet region while it increased again in the intrathoracic region. The highest value was in the cranial cervical region and the lowest was in the thoracic inlet region. The ventral width of tracheal rings decreased caudally until the level of the thoracic inlet region while it increased in the intrathoracic region. The cross sectional area decreased caudally until the thoracic inlet region while it increased again in the intrathoracic region. The highest value of the cross sectional area was in the cranial cervical region and the lowest value wasin the thoracic inlet region. The histological examination revealed that the tracheal wall consists of 4 distinct layers; mucosa, submucosa, cartilage and adventitia. The tunica mucosa consists of pseudostratified ciliated columnar epithelium resting on a basement membrane (Figs 2 and 3). Three types of cells, namely; basal cells, ciliated cells and mucous cells (goblet cell) were recognized. The lamina propria-and the tela submucosa are continuous with each other because of the absence of a muscularis mucosae. They consist of an irregular meshwork of collagen fibers containing many blood vessels and nerve endings (Figs 2 and 3). Tracheal glands in the form of coiled tubuloalveolar mucous glands were observed in the submuscosa (Fig 3).

The trachea is comprised of 50-51 pieces of Cshaped cartilaginous tracheal rings made up of hyaline cartilage. The fibrous layer of the perichondrium was strongly anchored to cartilage and was made by dense connective tissue containing fibroblasts and collagen fibers (Fig. 3). The tunica muscularis (tracheal muscle) was formed of typical smooth muscle fibers oriented transversely on the inner side of the tracheal ring. The tunica adventitia was comprised of loose connective tissues including elastic fibers and blended with the perichondrium (Fig. 3). A separate tracheal bronchus arise proximal to the tracheal bifurcation and entered the cranial lobe of the right lung is presented.

Table II. Mean \pm SD ( $n=6)$ of the cartilage thickness of the left (CTL), right (CTR), ventral (CTV) midpoints, ventral width of the tracheal ring (CWV) and cross section area (CSA) in the 4 regions of the trachea; cranial cervical (CCR), middle cervical (MCR), thoracic inlet (TIR) and the intrathoracic (ITR).

\begin{tabular}{lllll}
\hline Parameter & CCR & MCR & TIR & ITR \\
\hline CTR $(\mathrm{mm})$ & $2.12 \pm 0.18$ & $2.149 \pm 0.26$ & $1.85 \pm 0.21$ & $2.01 \pm 0.27$ \\
CTV $(\mathrm{mm})$ & $2.29 \pm 0.26$ & $2.16 \pm 0.25$ & $2.07 \pm 0.14$ & $2.17 \pm 0.24$ \\
CTL $(\mathrm{mm})$ & $2.29 \pm 0.41$ & $2.1 \pm 0.36$ & $2.10 \pm 0.44$ & $1.92 \pm 0.32$ \\
CWV $(\mathrm{mm})$ & $6.53 \pm 0.76$ & $6.79 \pm 0.51$ & $6.67 \pm 0.97$ & $6.66 \pm 0.92$ \\
CSA $\left(\mathrm{mm}^{2}\right)$ & $441.36 \pm 59.49$ & $430.43 \pm 83.72$ & $272.36 \pm 18.23$ & $395.65 \pm 23.59$ \\
\hline
\end{tabular}

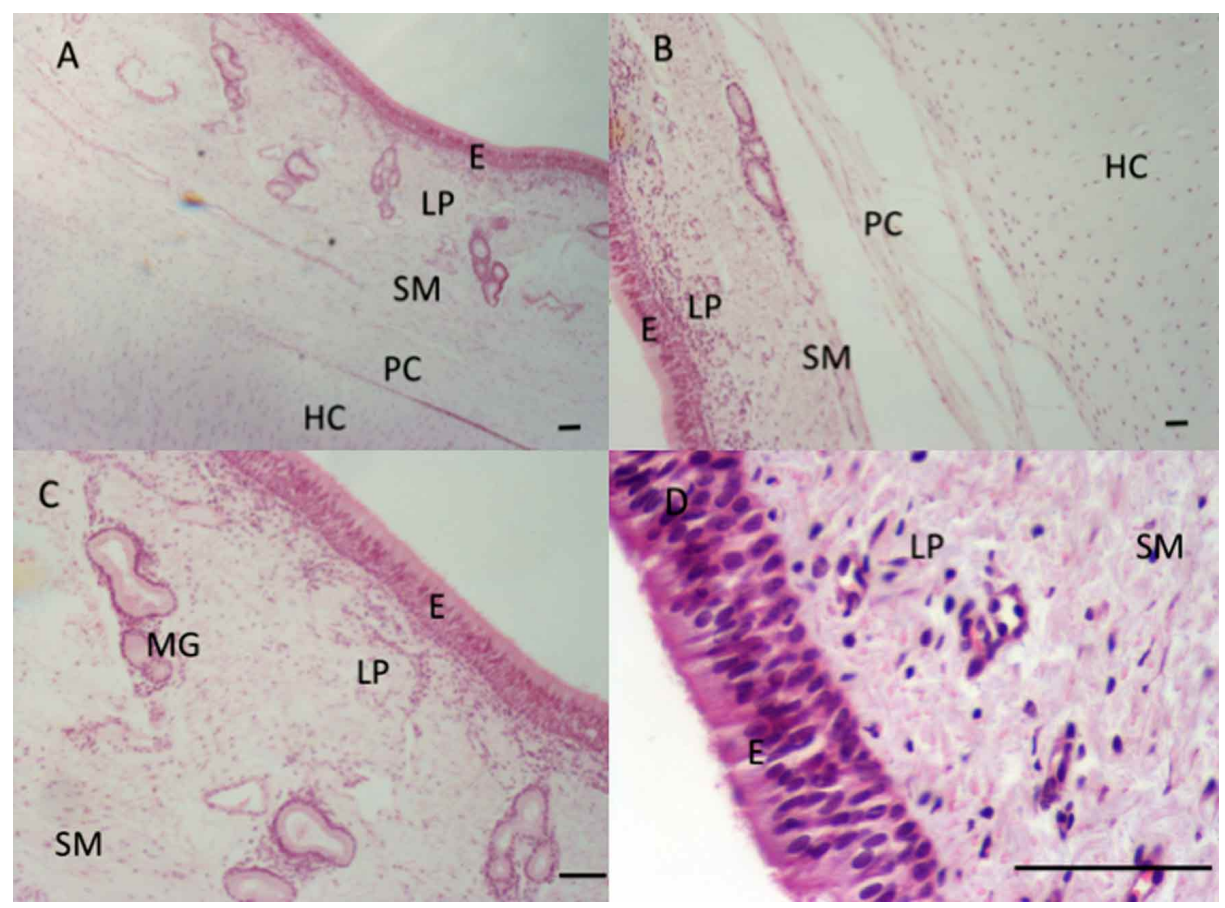

Fig. 2. Haematoxylin and eosin stained sections of Arabian oryx trachea: A and B (4X), C (10X) and D (40X). E: epithelium, LP: lamina propria, SM: submuscosa, PC: perichondrium, $\mathrm{HC}$ : hyaline cartilage, MG: mucous gland. Bar $=100 \mu \mathrm{m}$. 


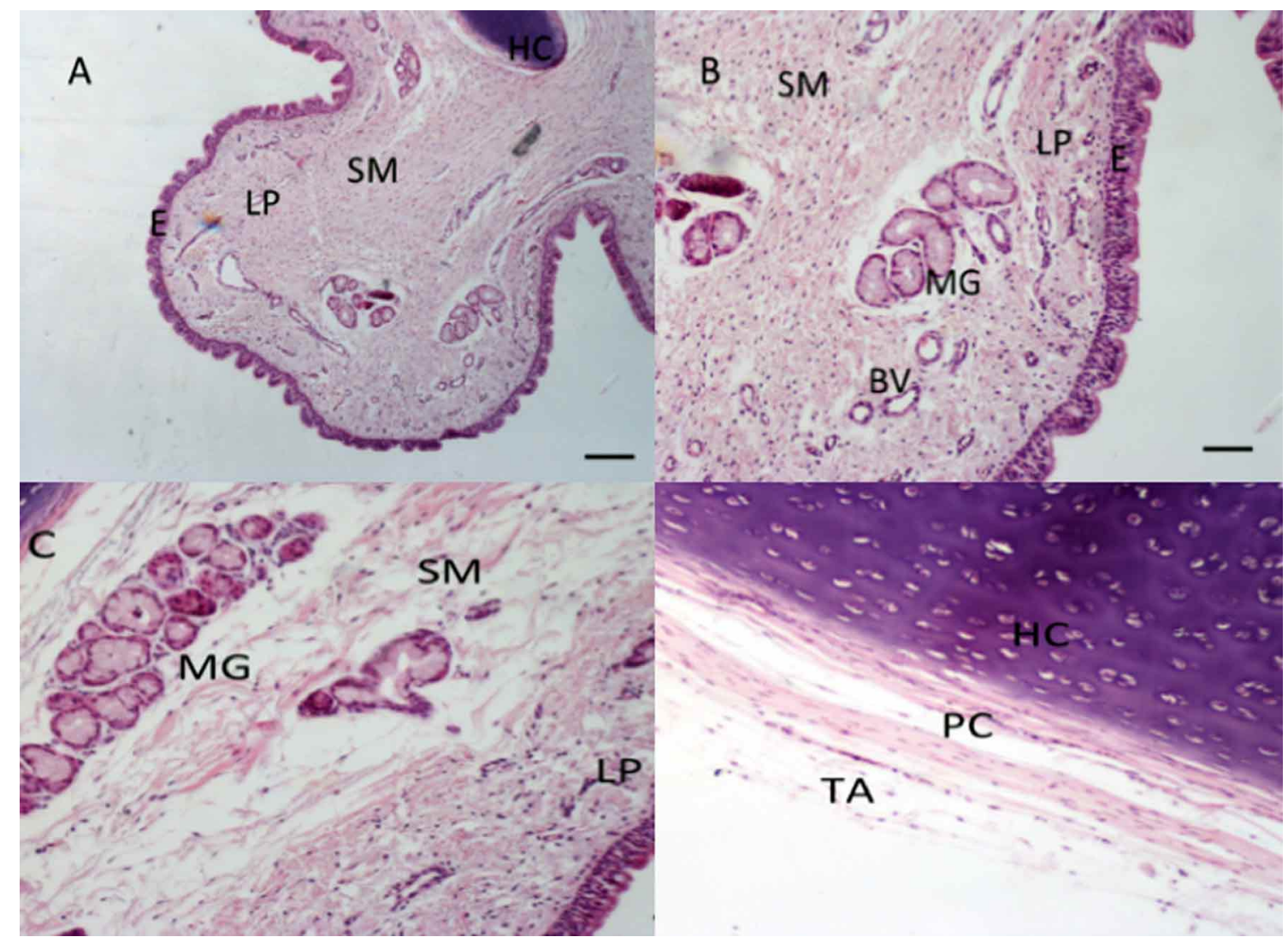

Fig. 3. Haematoxylin and eosin stained sections of Arabian oryx trachea (10X). E: epithelium, LP: lamina propria, SM: submuscosa, PC: perichondrium, HC: hyaline cartilage, MG: mucous gland, TA: tunica adventitia. Bar=100 $\mu \mathrm{m}$.

\section{DISCUSSION}

In the adult male Arabian oryx, the average tracheal length and total number of tracheal rings is being reported here for the first time. The tracheal length and number of rings were $54.1 \mathrm{~cm} \pm 0.73$ and 50-51, respectively. Fusion between neighboring rings was observed within all tracheal regions. Although, not consistent in all specimens examined, tracheal ring fusion occurred mostly in the cranial cervical region. It has been suggested that tracheal rings of this region are most affected by neck movements resulting in its fusion over time (Morgan et al., 1986). The mean ratios of IT/IV and OT/OV diameters lie between 0.75 and 0.98 . These values are important in the determination of the shape and uniformity of the tracheal lumen. Results obtained here indicate that the trachea has a near-circular CSA in the Arabian oryx. Art \& Lekeux suggested that if IT/IV and OT/OV ratios are below 1.3, then the trachea would assume a circular CSA.
In cases where stenosis is suspected, actual CSA measurement is preferred to estimate the percentage of luminal diameter at the stenosis site because it is considered more accurate irrespective of the shape of the tracheal lumen (Dapanoglu \& Kara). In this study, digital image analysis was used to determine the actual CSA with accurate and reliable results. The lowest values for tracheal diameter and CSA were seen at the level of the thoracic inlet. At this level, the CSA was $38.29,36.72$ and $31.16 \%$ smaller than that in the cranial cervical, the caudal cervical and intrathoracic regions, respectively. Similar results were reported in the trachea of juvenile camels (Al-Zghoul et al.; Dapanoglu \& Kara). At the thoracic inlet, the trachea changes course from caudoventrally to caudodorsally passing the thoracic cavity causing this narrowing of the lumen. In addition, the bony boundaries of the thoracic inlet cause further narrowing of the lumen at this site (Dapanoglu \& Kara). 
Results of this study indicate that the cartilage at the right and left midpoints is thinner at the level of the thoracic inlet than in other regions of the trachea. It has been reported that thinner cartilage rings contain reduced amounts of glycosaminoglycan and water; therefore, a more flaccid and weaker cartilage which could be more susceptible to damage (Dallman \& Brown). Although, tracheal collapse has not been reported in the Arabian oryx, this finding suggests that tracheal collapse would occur most likely at the thoracic inlet.

Similar to other ruminants, histological analysis revealed that the wall of the trachea is consisted of four histological layers: a mucosa made of pseudostratified epithelium and lamina propria, submuscosa made of dense irregular connective tissues, a hyaline cartilage layer and tunica adventitia made of loose connective tissues.
Results of this study provide anatomist, clinicians and anesthetists with valuable information about the tracheal length and diameter, cartilage numbers and thickness in different regions of the trachea of the Arabian oryx. These data could be useful in the diagnosis of certain tracheal diseases and aid in the selection of the proper length and size of endotracheal and tracheostomy tubes in preparation for general anesthesia and in emergency situations.

\section{ACKNOWLEDGEMENTS}

The authors would like to thank all the staff of the Shaumari Nature Reserve, Jordan University of Science and Technology Deanship of Research and the Veterinary Health Center of the Faculty of Veterinary Medicine for their assistance.

AL-ZHGOUL, M. B.; DALAB, A. H. S.; ABDULHAKEEM, E.; ISMAIL, Z. B. \& THANAIN, A. Tráquea del Orix de Arabia $($ Oryx leucoryx): un análisis descriptivo y morfométrico. Int. J. Morphol., 31(3):813-818, 2013.

RESUMEN: El objetivo fue describir las características anatómicas e histológicas distintivas de la tráquea del Orix de Arabia (Oryx leucoryx). Fueron medidos el número de anillos traqueales y la longitud traqueal. El diámetro, grosor y área de la sección transversal (AST) del anillo traqueal fueron determinados en cuatro regiones (cervical craneal (CCR), medio cervical (MC), entradas torácicas (ET) e intratorácica (EIT)). También se realizó en los anillos traqueales el análisis histológico. La longitud media de la tráquea fue de $54,1 \pm 0,73 \mathrm{~cm}$, mientras que el número de anillos traqueales varió desde 50 hasta 51 . Las mediciones del anillo traqueal (diámetro, grosor y AST) fueron menores en la región de la entrada torácica. La relación de los diámetros transversal exterior a vertical exterior y transversal interno a vertical interno osciló entre 0,75 y 0,98. El análisis histológico reveló que la pared de la tráquea se compone de cuatro capas: mucosa de epitelio pseudoestratificado y lámina propia, submuscosa de tejido conectivo denso irregular, cartílago hialino y túnica adventicia de tejido conectivo laxo.

PALABRAS CLAVE: Oryx leucoryx; Tráquea; Análisis descriptivo; Análisis morfométrico.

\section{REFERENCES}

Al-Zghoul, M. B.; Ismail, Z. B.; Al-Rukibat, R. K. \& Al-Majali, A. M. A quantitative study on the trachea of young arabian camels (Camelus dromedarius). J. Camel Pract. Res., 13(13):129-33, 2006.

Art, T. \& Lekeux, P. The effect of shape, age and extension on the compliance of equine tracheal segments. Vet. Res. Commun., 15(2):135-46, 1991.

Behl, S. \& Watt, J. H. W. Prediction of tracheostomy tube size for paediatric long-term ventilation: an audit of children with spinal cord injury. Br. J. Anesth., 94(1) :88-91, 2005.

Brodsky, J.; Macario, A. \& Mark, J. B. Tracheal diameter predicts double-lumen tube size: A method for selecting left doublelumen tubes. Anesth. Analg., 82(4):861-4, 1996.
Chunder, R.; Nandi, S., Guha, R. \& Satyanarayana, N. A morphometeric study of human trachea and prinicipal bronchi in different age groups in both sexes and its clinical implications. Nepal Med. Coll. J., 12(4):207-14, 2010.

Dallman, M. J. \& Brown, E. M. Statistical analysis of selected tracheal measurements in normal dogs and dogs with collapsed trachea. Am. J. Vet. Res., 45(5):1033-7, 1984.

Dapanoglu, I. \& Kara, M. E. A quantitative study on the trachea of the dog. Anat. Histol. Embryol., 30(1):57-9, 2001.

Eljarah, A.; Al-zghoul, M.; Jawasreh, K.; Ababneh, M.; Alsumadi, M.; Elhalah, A. \& Bani Ismail, Z. Characterization of male reproductive anatomy of the endangered Arabian oryx (Oryx leucoryx). Theriogenolgy, 78(1):159-64, 2012a. 
AL-ZHGOUL, M. B.; DALAB, A. H. S.; ABDULHAKEEM, E.; ISMAIL, Z. B. \& THANAIN, A. Arabian oryx (Oryx leucoryx) trachea: a descriptive and morphometric analysis. Int. J. Morphol., 31(3):813-818, 2013.

Eljarah, A.; Al-zghoul, M.; Jawasreh, K.; Ismail, Z. A.; Ababneh, M. M.; Elhalah, A. \& Alsumadi, M. M. Female reproductive tract anatomy of the endangered Arabian oryx (Oryx leucoryx) in Jordan. Ital. J. Anat. Embryol., 117(3):167-74, 2012 b.

Ivana, C. \& William, P. Quantitative Anatomy of the Trachea of the Giraffe (Giraffa camelopardalis rothschildi). Int. J. Morphol., 27(3):905-8, 2009.

Kalache, K. D.; Nishina, H. D. \& Hanson, M. A. Visualization and measurement of tracheal diameter in the sheep fetus: An ultrasound study with stereomicroscopic correlation. Fetal Diagn. Ther., 16(6):342-5, 2001.

Knudson, R. J. Effect of muscle constriction on flow-limiting collapse of isolated canine trachea. J. Appl. Physiol., 38(1):12531, 1975.

Kumar, P.; Singh, G.; Nagpal, S. K. \& Dhingra, L. D. Tracheal dimensions of camel. Indian J. Anim. Sci., 62:140-1, 1992.

Loewen, M. S. \& Walner, D. L. Dimensions of rabbit subglottis and trachea. Lab. Anim., 35(3):253-6, 2001.

Morgan, J. P.; Miyabayashi, T. \& Choi, S. Cervical spine motion: radiographic study. Am. J. Vet. Res., 47(10):2165-9, 1986.

Peshin, P. K. \& Prakash, P. A note on the quantitative anatomical study of the trachea in the Indian Buffalo (Bubalus bubalis). Anat. Anz., 138(5):463-7, 1975.
Correspondence to:

Dr. Mohammad Borhan Al-Zghoul, DVM, Ph. D.

Department of Basic Medical Veterinary Sciences

Faculty of Veterinary Medicine

Jordan University of Science and Technology

P.O. Box 3030

Irbid 22110

JORDAN

E-mail: mbalzghoul@kfu.edu.sa

Dr. Mohammad Borhan Al-Zghoul

Department of Anatomy

Faculty of Veterinary Medicine and Animal Resources

King Faisal University

Al-Ihssa 31982

Kingdom of Saudi Arabia

E-mail: alzghoul@just.edu.jo

Received: 10-01-2013

Accepted: 29-04-2013 